\title{
THE INFLUENCE OF PERSONALITY ACCENTUATION ON DRUG ADDICTION AMONG STUDENTS
}

\author{
${ }^{1}$ Elena Aleksandrovna Cheverikina, ${ }^{2}$ Andrei Vasilyevich Leifa, \\ ${ }^{3}$ Nataliya Alekseyevna Kora, ${ }^{4}$ Juliya Valerevna Badalyan, \\ ${ }^{5}$ Elena Anatolyevna Burdukovskaya and ${ }^{6}$ Ekaterina Viktorovna Pavlova \\ ${ }^{1}$ Institute of Pedagogic and Psychology of Professional Education of Russian Academy of Education, \\ Tatarstan, 420039, Kazan, Isaeva Street, 12, Russia \\ ${ }^{2}$ Blagoveschensk State Pedagogical University, Russia, Amur Region, 675000, Blagoveschensk, Lenin Street, 104, Russia \\ ${ }^{3,4,5,6}$ Amur State University, Russia, Amur Region, 675027, Blagoveschensk, Ignatyevskoe Shosse, 21, Russia
}

Received 2014-05-15; Revised 2014-05-30; Accepted 2014-06-27

\begin{abstract}
To identify character accentuation students who are prone to addiction will allow to adjust their socialization process during the training period in order to increase its effectiveness, as well as it will contribute to the creation of effective psycho-educational programs aimed at reducing the level of their addiction to drugs. Objective: To identify the influence of experimental character accentuation susceptibility to drug addiction among students. The study is based on concept of accented personalities by K. Leonhard and typology of accented personalities by A.E. Lichko. Psychological testing was as an empirical research method. Data processing was performed using the Statistical Package for Social Sciences (SPSS) v.17. It was found out that the students of higher education compared to students of secondary vocational education had susceptibility to drug addiction associated with less accentuation of character. This can be explained by the fact that those who are going to the universities to study are more socially adapted, they have a higher level of self-control and self-discipline, able by virtue of age and education to control outbursts of emotions and behavior. The findings of the study data will allow to adjust psycho-educational programs aimed at reducing the propensity to addiction among students based on character accentuation detected among students of higher and vocational education.
\end{abstract}

Keywords: Students, Susceptibility to Drug Addiction, The Accentuation of Character, Reducing Addiction, Psychological and Pedagogical Work with Students

\section{INTRODUCTION}

Many researchers who have studied the characteristics of addiction to psychoactive substances in adolescents indicate the influence of personality accentuation on the possibility of forming propensity to alcoholism and drug addiction. K. Leonhard notes that alcohol addiction can most likely emerge from the excitable, demonstrative personalities (Leongard, 2001). The researchers stressed that an important role in the development of addictive behavior play specific types of character accentuation. Studies have shown that hypertive, cycloid, schizoid and epileptoid hysteroid teenagers are prone to addiction and depending on the type of accentuation manifestations of alcohol and drug addiction will be of a different character (Lichko, 2010; Egorov, 2002).

There are data on the prevalence of common hypertive and conformal accentuants, along with epileptoid in anesthetized adolescent environment (Romanov and Gorpinenko, 2001) in published issues. There are studies, which presents data on the prevalence Corresponding Author: Elena Aleksandrovna Cheverikina, Institute of Pedagogic and Psychology of Professional Education of Russian Academy of Education, Tatarstan, 420039, Kazan, Isaeva Street, 12, Russia 
of different types of accentuation in different forms of addiction: Drug addiction among patients of ephedron most common are hysteroid accentuants and of opium addicts-epileptoidones (Shabanov, 2009).

Identifying the impact of character accentuation on the propensity to addiction will allow students to adjust their socialization process during the training period in order to increase its effectiveness, as well as vocational training will establish effective psychoeducational programs aimed at reducing the level of their addiction to drugs.

\section{MATERIALS AND METHODS}

Object of research: Students of the higher and secondary professional education inclined to drug addiction.

Object of research: Features of influence of accentuation of character of students of the higher and secondary vocational education on their tendency to drug addiction.

Research problems: To do research of students of the higher and secondary professional education using the techniques corresponding to an objective; to reveal influence of accentuation of character on tendency to drug addiction of students of an average and higher education.

The hypothesis of research is that the students of secondary professional education have an accentuation of character which is more strongly interconnected with tendency to drug addiction. The students of the higher and secondary professional education with increasing level of tendency to drug addiction are influenced by an unstable self-assessment, inability to control the emotions and acts, inability to assume responsibility, to define the purposes, to make decisions and consistently to realize them.

The communicative skills, which are not formed yet, skills of effective both individual and group activity, skills of concentration influence the increase of level of tendency to drug addiction among the students of secondary professional education who are inclined to drug addiction. They have weak commitment, the spiteful attitude towards the people, insufficient discipline, standards of behavior and following to ethical standards.

Research in which 186 students of the Kazan medical college, 21 students of Academy of social education, Kazan and 135 students of the Amur state university, Blagoveshchensk took part was conducted.

Research was conducted with use of the following techniques:

- Shmishek's questionnaire for identification of accentuation of character
- Questionnaire "Tendency to addiction" for identification of the students inclined to drug addiction

\section{RESULTS}

It is established that students of secondary professional education are more inclined to drug addiction (high level of tendency is revealed at $25 \%$ of students of secondary professional education and at students of higher education-at 15\%) (Fig. 1).

For detection of features of accentuation of students' character with different level of tendency to drug addiction we statistically established reliable distinctions of average values on scales of a questionnaire of Shmishek for students of the higher and secondary professional education (Stjyudent's T-criterion).

The reliabilities of distinction of average values of students of higher education with different level of tendency to drug addiction are presented in Table $\mathbf{1 .}$

For students of higher education with low and high tendency to drug addiction reliable distinctions of average values only on a scale Emotionality are revealed. Data on a scale Emotionality allow to say that students of higher education with low tendency to drug addiction differ for their responsiveness, the humane attitude to the world, softness and warm-heartedness. They are acute and their developed intuition allows them to define almost unmistakably the attitude of people around to them. The emotional personality can't be influenced by an only event, it can't "be infected" with fun or sad mood without the reason. The nervous shock can make strong influence and cause a depression, thus weight of a depression corresponds to weight of an event. Success of process of their socialization is promoted by such traits, as deep, sincere feelings, ability to empathy, ability to rejoice to progress of other people, high discipline, working capacity, selfcriticism and the developed esthetic taste and also constant aspiration to self-education and self-development. Students of higher education with high tendency to drug addiction somewhat lose these traits of character. The condition of emotional depression, estrangement is more peculiar to them, any of their activity emotionally colorless, stereotypic. In the course of their socialization such negative features as tendency to long experience of feelings, vulnerability (excessive sensitivity to critical remarks, painful sensitivity), jealousy or anger flashes, suspiciousness, confusion in difficult situations and also high subjectivity of estimates, "partiality" start being shown.

The obtained data are confirmed also by the correlation analysis by means of coefficient of correlation of Pearson. Its results are presented in Table 2 . 


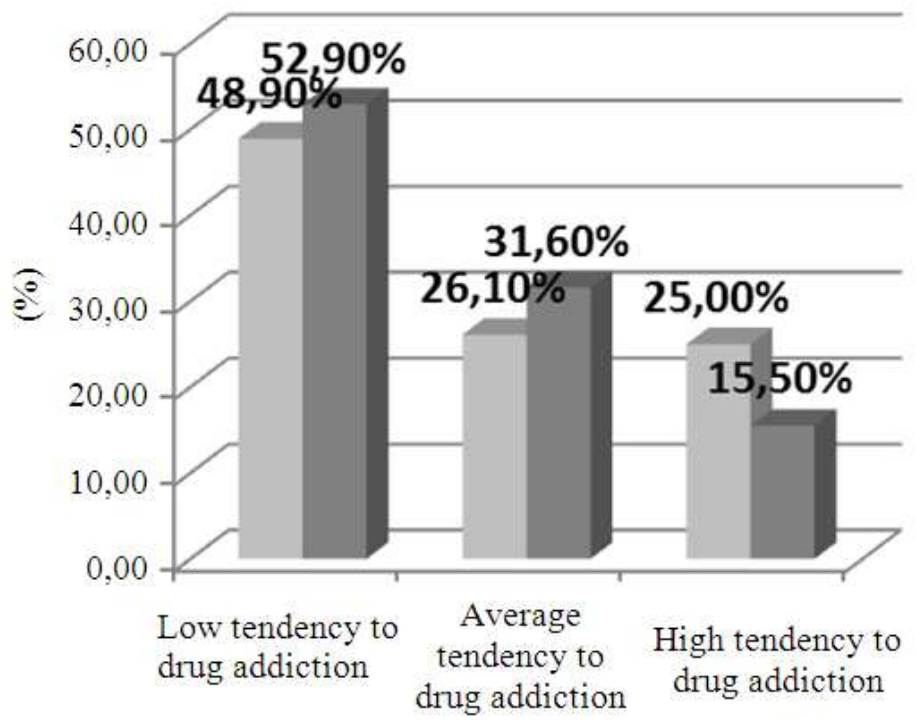

Secondary professional education

Higher professional education

Fig. 1. Number of students of the higher and secondary professional education with different level of tendency to drug addiction (\%)

Table 1. The reliabilities of distinction of average values of students of higher education, who are inclined to drug addiction by method of Shmishek

\begin{tabular}{|c|c|c|c|}
\hline & \multicolumn{3}{|c|}{ Inclination to drug addiction } \\
\hline & Low/high & Low/average & Average/high \\
\hline Hypertiveness & $-0,472$ & $-1,504$ & 0,683 \\
\hline Emotionality & $3,613^{*}$ & 0,095 & $2,873^{*}$ \\
\hline Anxietyt & 0,721 & 0,826 & 0,090 \\
\hline Demonstrativeness & $-0,010$ & $-2,325^{*}$ & 1,702 \\
\hline Distimidness & $-1,782$ & $-1,026$ & $-0,801$ \\
\hline Jamming & 0,076 & $-1,074$ & 0,817 \\
\hline Pedantry & $-0,567$ & $-0,487$ & $-0,049$ \\
\hline Cyclotary & $-1,272$ & $-1,602$ & 0,247 \\
\hline Excitability & $-1,689$ & $-1,449$ & $-0,269$ \\
\hline Exaltation & 1,150 & 0,132 & 0,771 \\
\hline
\end{tabular}

*- The differences of average data are reliable at level $\mathrm{p} \leq 0,05$

Table 2. Interconnection of accentuation of the personality with the inclination to drug addiction among students of higher education

\begin{tabular}{ll}
\hline & Inclination to drug addiction \\
\hline Hypertivness & $-0,018$ \\
Emotionality & $-0,289^{* *}$ \\
Anxiety & $-0,085$ \\
Demonstrativeness & $-0,040$ \\
Distimidness & 0,137 \\
Jamming & $-0,038$ \\
Pedantry & 0,060 \\
Cyclotary & 0,063 \\
Excitability & 0,145 \\
Exaltation & $-0,118$ \\
\hline
\end{tabular}

**- Correlation is significant at level $\mathrm{p} \leq 0,01$

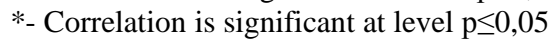


Reliability of differences in average secondary vocational education students with different levels of inclination to drug addiction are presented in Table 3.

For students of secondary professional education with low and high level of tendency to drug addiction reliable distinctions of average values on scales of Hypertiveness, Emotionality, Cyclotary, Excitability, Exaltation are established. Features of persons with accentuation of emotional, cyclotive and excitable types are described above.

Data on a scale of Hypertiveness allow to draw a conclusion that students of secondary professional education with low tendency to drug addiction are active, vigorous, optimistically adjusted, with a high vitality. They are kind and sympathetic. They differ in talkativeness, "intellectual mobility", tendency to witty tricks. They are resourceful, are able to adapt to difficulties. They endure failures, but they don't unsettle them. They try to be leaders in groups. Success of their socialization is promoted by such traits, as optimism, cheerfulness, vigor, sociability, initiative, enterprise, resourcefulness in non-standard, stressful situations, ability to cause the trust, the developed sense of humor, high motivation of achievements, independence of opinions and estimates of people around, being open-minded. With increase of level of tendency to drug addiction among students of secondary professional education carelessness starts being shown. Because of instability of attention and insufficient persistence their interests become superficial. Intolerance to any restriction of freedom, to criticism towards them, increases. Their attitude to rules and duties becomes thoughtless. Such students aren't legible in a choice of acquaintances, are tired of a habitual circle of contacts rather quickly, look for the new companies. Success of their socialization is interfered by such traits, as the general concern, fussiness, inability to long concentration of attention, dispersion in thoughts and affairs (desire to be always in time in combination with continuous haste and delay), absence of aspiration to finish the begun business, tendency to unjustified risk (adventurism), inadequate ease concerning vital problems, rashness of behavior, statements, violation of ethical standards (vulgarity, roughness), inconstancy in the interpersonal relations, illegibility in contacts, low discipline, the irresponsibility, poorly developed call of duty and ability to repentance, lack of self-criticism.

Data on a scale of Exaltation say that the students of secondary professional education with low level of tendency to drug addiction have rather high speed of course of mental processes, their mentality is flexible. Even insignificant events can cause strong emotional reaction in them, positive or negative depending on the maintenance of an event. Exaltation is based on altruistic, than egoistical motives more often. Attachment to close friends, pleasure for them, for their good luck can be extremely strong. Success of their socialization is promoted by such features, as sociability, emotionality, good nature, sincerity, "acute moral eyesight", keenness, readiness to help. Students of secondary professional education with high tendency to drug addiction are often emotionally depressed, any their activity has weak emotional coloring. Their successful socialization is interfered by such features, as dependence on mood change (during conversation they can take offence without explanations and a visual reason, become angry), the weakened selfcontrol (irritability, irascibility, impatience), avoiding of difficulties, tendency to a self-accusation, impossibility of the long forecast of activity, egoism.

The obtained data are confirmed also by the correlation analysis by means of coefficient of correlation of Pearson. Its results are presented in Table 4.

Table 3. Reliabilities of differences in average data among students of secondary vocational education inclined to drug addiction, by method of Shimshek

\begin{tabular}{llll}
\hline & \multicolumn{2}{c}{ Inclination to drug addiction } & \\
& Low/high & Low/average & Average/high \\
\hline Hypertiveness & $1,946^{*}$ & 0,539 & 1,005 \\
Emotionality & $2,799^{*}$ & 0,156 & $2,055^{*}$ \\
Anxiety & 1,220 & $-0,547$ & 1,496 \\
Demonstrativeness & 0,433 & 0,830 & $-0,393$ \\
Distimidness & $-1,767$ & $-0,296$ & $-1,096$ \\
Jamming & 0,495 & 0,162 & 0,226 \\
Pedantry & 1,182 & $-0,294$ & 1,231 \\
Cyclotary & $2,358^{*}$ & $-2,057^{*}$ & $3,291^{*}$ \\
Excitability & $-2,020^{*}$ & $-2,060^{*}$ & 0,329 \\
Exaltation & $2,872^{*}$ & $-0,553$ & $2,835^{*}$ \\
Sincerity & $-0,634$ & 0,398 & $-0,922$ \\
\hline
\end{tabular}

*- The differences of average data are reliable at level $\mathrm{p} \leq 0,05$ 
Table 4. Interconnection of accentuation of personality with inclination to drug addiction among students of secondary vocational education. (coefficient of correlation of Pearson)

\begin{tabular}{ll}
\hline & Inclination to drug addiction \\
\hline Hypertiveness & $-0,149^{*}$ \\
Emotionality & $-0,250^{* *}$ \\
Anxiety & $-0,096$ \\
Demonstrativeness & $-0,016$ \\
Distimidness & 0,087 \\
Jamming & $-0,076$ \\
Pedantry & $-0,125$ \\
Cyclotary & $-0,163^{*}$ \\
Excitability & 0,111 \\
Exaltation & $-0,226^{* *}$ \\
\hline **- Correlation is significant at level $\mathrm{p} \leq 0,01$ \\
*-Correlation is significant at level $\mathrm{p} \leq 0,05$
\end{tabular}

\section{DISCUSSION}

Foreign scientists, considering a problem of drug addiction, the main directions of the researches see in studying of neuropsychological consequences of the use of narcotic substances, (Venkatesan et al., 2006), interconnection of drug addiction and risk of incidence of a human immunodeficiency virus (Dévieux et al., 2009) various opportunities of medicamental treatment of drug addiction (Perla and Knutson, 2005). Features of addictive behavior in the student's environment were studied from the point of view of its prevalence and the factors influencing its formations and doing harm to health of students (Houri and Hammoud, 2005). Researches of features of students of higher education with deviations of mental development were conducted. Their disadaptation can become the reason of drug addiction (Yahaya et al., 2009). Prevalence of types of accentuation of the character assuming possible consumption of psychoactive agents, among students of various vocational guidance (Halepo and Molotkov, 2009) was studied.

The Russian scientists pay much more attention to studying of the psychological reasons of formation of drug addiction, including character accentuation. Formation of tendency to addictive behavior among the senior teenagers with different types of accentuation of character (Kondrashkova and Kuvichkina, 2013) was studied. Accentuation of character were considered as risk factor of emergence of a drug addiction (Polyakova, 2011), as a factor of addictive identity of the personality at young age (Smoilik, 2013). Taking into account accentuation of character the analysis of psychological predisposition of students of Smolensk state academy of physical culture, sports and tourism to the use of narcotic substances (Polyarkova, 2011) was carried out.

The analysis of researches showed that generally the interconnection of accentuation of character and tendency to alcoholic and drug addiction was studied among teenagers and generally within clinical psychology and narcology. The researches directed on studying of influence of accentuation of character on tendency to drug addiction among students of the higher and secondary vocational education are not enough for a clear understanding of a problem.

\section{CONCLUSION}

The conducted research allowed to draw to a conclusion that among students of higher education in comparison with students of secondary vocational education tendency to narcotic substances addiction is less connected with character accentuation. It can be explained by the fact that more socially adapted persons having higher level of self-checking and self-discipline, able owing to age and education to control flashes of emotions and a deviation in behavior are going to study to the establishments of higher education.

\section{RECOMMENDATION}

When developing the psychology and pedagogical programs directed on decrease in level of tendency to drug addiction for students of the higher and secondary vocational education it is necessary to place emphasis on formation of an adequate, stable selfassessment, development of ability to control the emotions and acts, abilities to assume responsibility, to define the purposes, to make decisions and consistently to realize them. It is very important for students to form the positive attitude to themselves, to other people, to life as a whole.

During the work on decrease of level of tendency to drugs addiction among students of secondary vocational education it is important to pay attention to such aspects, as formation of communicative skills, skills of effective both individual and group activity, skills of concentration. It is important to develop commitment, the benevolent attitude towards people, discipline, standards of behavior and following to ethical standards in them.

However the demanding further research of the questions connected with detection of psychological, social and psychological and social factors, influencing formation of tendency to drug addiction are perspective. 


\section{REFERENCES}

Dévieux, J.G., R.M. Malow, R. Rosenberg, M. Nair and D.M. Samuels et al., 2009. Borderline personality symptoms and human immunodeficiency virus risk in alcohol and other drug abusing adolescent offenders. Am. J. Infect. Dis., 5: 31-39. DOI: 10.3844/ajidsp.2009.31.39

Egorov, A.Y., 2002. Personal features of teenagers with heroin and alcoholic dependence. Proceedings of the 7th of the All-Russian Scientific and Practical Conference Education in Russia: MedicoPsychological Aspect, (MPA’ 02), pp: 75-77.

Halepo, O.V. and O.V. Molotkov, 2009. Prevalence of types of aktsentuation of the character assuming possible consumption of psychoactive agents, among students of various vocational guidance. Proceedings of the 7th of the International Conference MedicoSocial Ecology of the Personality: State and Prospects, (PSP' 09), pp: 62-65.

Houri, A. and M. Hammoud, 2005. Addictive behaviors amongst university students: Contributing factors, student's perception and addiction rates. J. Soc. Sci., 1: 105-113. DOI: 10.3844/jssp.2005.105.113

Kondrashkova, E.N. and M.V. Kuvichkina, 2013. Formation of tendency to addiktivny behavior at the senior teenagers with different types of aktsentuation of character. Messenger Edu. Methodical Associat. Professional Pedagogical Edu., 1: 212-219.

Leongard, K., 2001. Aktsentuirovanny Persons. 1st Edn., Moscow, Eksmo-Press, pp: 448.

Lichko, A.E., 2010. Psikhopatiya and a Character Aktsentuation at Teenagers. 1st Edn., Petersburg, Speech, pp: 256.

Perla, R.J. and E.L. Knutson, 2005. Delftia acidovorans bacteremia in an intravenous drug abuser. Am. J. Infect. Dis., 1: 73-74. DOI: 10.3844/ajidsp.2005.73.74
Polyakova, S.A., 2011. Aktsentuation of character as risk factor of emergence of a drug addiction. Proceedings of the 8th of Interuniversity Scientific and Practical Conference of Young Scientists and Students Youth and Formation of the XXI Century, (YFC' 11), pp: 473-478.

Polyarkova, I.I., 2011. The analysis of psychological predisposition of students of Smolensk state academy of physical culture, sports and tourism to the use of narcotic substances. Proceedings of the International Scientific and Practical Conference Modern Means of Increase of Physical Efficiency of Athletes, (YFC' 11), pp: 119-124.

Romanov, D.V. and S.V. Gorpinenko, 2001. Personal mechanisms of formation of drug addiction in the organization of interdepartmental interaction for drug addiction prevention, treatment, rehabilitation and employment of drug addicts. Experience Samara Region.

Shabanov, P.D., 2009. Drug addiction: Patopsikhologiya, Clinic, Rehabilitation. 1st Edn., Petersburg: Publishing house "Fallow deer, pp: 368.

Smoilik, N.A., 2013. Aktsentuation of character as a factor of addiktivny identity of the personality at youthful age. Volga Sci. Messenger, 11: 146-149.

Venkatesan, A., O. Selnes, V. Wojna, J.C. McArthur and A. Nath et al., 2006. Neuropsychological Consequences of HIV and Drug Ause. Am. J. Infect. Dis., 2: 90-97. DOI: 10.3844/ajidsp.2006.90.97

Yahaya, A., J. Ramli, S. Hashim, M.A. Ibrahim and Z. Zakaria et al., 2009. Analysis of students with psychiatric disabilities in higher education. J. Soc. Sci., 5: 362-369. 